\title{
Hospitals During Recession and Recovery: Vulnerable Institutions and Quality at Risk
}

Jeremy B. Sussman, MD, $\mathrm{ms}^{1,2}$ Lakshmi K. Halasyamani, $\mathrm{mo}^{3}$ Matthew M. Davis, MD, MAPp ${ }^{1,2,4}$

\author{
${ }^{1}$ Robert Wood Johnson Clinical Scholars Program, University of Michigan, Ann Arbor, Michigan. \\ ${ }^{2}$ Division of General Medicine, University of Michigan, Ann Arbor, Michigan. \\ ${ }^{3}$ Saint Joseph Mercy Health System, Ann Arbor, Michigan. \\ ${ }^{4}$ Division of General Pediatrics and Gerald R. Ford School of Public Policy, University of Michigan, \\ Ann Arbor, Michigan.
}

Disclosure: Nothing to report.

For generations, American hospitals have been considered recession-proof, but there is reason to believe the current economic crisis is an exception. Hospitals have shown declining financial margins and decreased admissions. The severe recession has adversely affected many hospitals' finances, creating a risk of closure and constraining plans for expansion. We believe there is also a risk of harming clinical quality, through decreased staffing that may limit the momentum of the hospital quality movement, especially in fiscally vulnerable institutions. We consider ways the federal government could aid hospitals by promoting hospital quality while providing employment. Journal of Hospital Medicine 2010;5:302-305. $\odot 2010$ Society of Hospital Medicine.

KEYWORDS: economics, hospital, quality, recession.

With the United States mired in its most severe recession in decades, stories of hospital struggles have emerged. Beaumont Hospital, located near the headquarters of major automakers and several assembly plants outside Detroit, recently cut hundreds of jobs and put major construction on indefinite hold. ${ }^{1}$ The CEO of Boston's Beth Israel Deaconess Medical Center made an agreement with employees to take large cuts in pay and vacation time to prevent laying off $10 \%$ of the staff. ${ }^{2}$ The University of Chicago Medical Center made plans to limit the number of emergency room beds, thereby decreasing low-reimbursing emergency admissions while making beds available for higher-paying elective hospitalizations. $^{3}$

What is surprising about these stories is that hospitals have long been considered recession-proof. Yet, with onehalf of US hospitals having reduced their staff to balance their budgets ${ }^{4}$ and with hospitals' financial margins falling dramatically, ${ }^{5}$ economic struggles are now a widespread problem.

Furthermore, it is difficult to determine if hospitals' clinical care has been damaged by the recession. The measurement of hospital quality is new and still under-developed: there is virtually no reliable information on hospital quality from previous recessions, and even now it will be difficult to assess quality in "real time."

Critics of waste and excess in the US health care system may see tough economic times as a Darwinian proving ground for hospitals, through which efficiency will improve and poor performers will close their doors. But more likely, hospital cutbacks will risk the quality and safety of health care delivery. For reasons of both public health and fiscal impact on communities, state and federal leaders may need to watch these trends closely to design and to be ready to implement potential government remedies for hospitals' fiscal woes.

In this commentary, we describe how hospitals have fared historically during recessions, how this recession could have different effects-first fiscally, then clinically, and we examine policy options to mitigate these untoward effects.

\section{Decades of Recession-Proof Hospitals}

During the Great Depression, hospital insolvency was a national problem that prompted federal and state aid. Keeping hospitals alive was a critical policy goal and proved central to the early development of health insurance that focused on payment for hospital care. ${ }^{6}$

Since WWII, growth in America's hospitals has been only loosely related to national macroeconomic trends, with other changes like technological innovations and the advent of managed care far more influential to hospital finances. In fact, during recessions, hospital care spending growth often escalates in tandem with worsening unemployment (Figure 1). One explanation for this phenomenon is that economic pressures lead to declining primary care utilization, with adverse consequences for individuals' health. ${ }^{7}$

\section{Hospitals' Current Fiscal Vulnerability}

However, the current recession is the worst in 70 years. Every method of income generation available to hospitals appears at risk, including reimbursement per discharge (70\% of hospitals report moderate or significant increases in uncompensated care), number of inpatient admissions (over one-half report a moderate or significant decrease), difficulty obtaining bonds $(60 \%$ report at least significant 


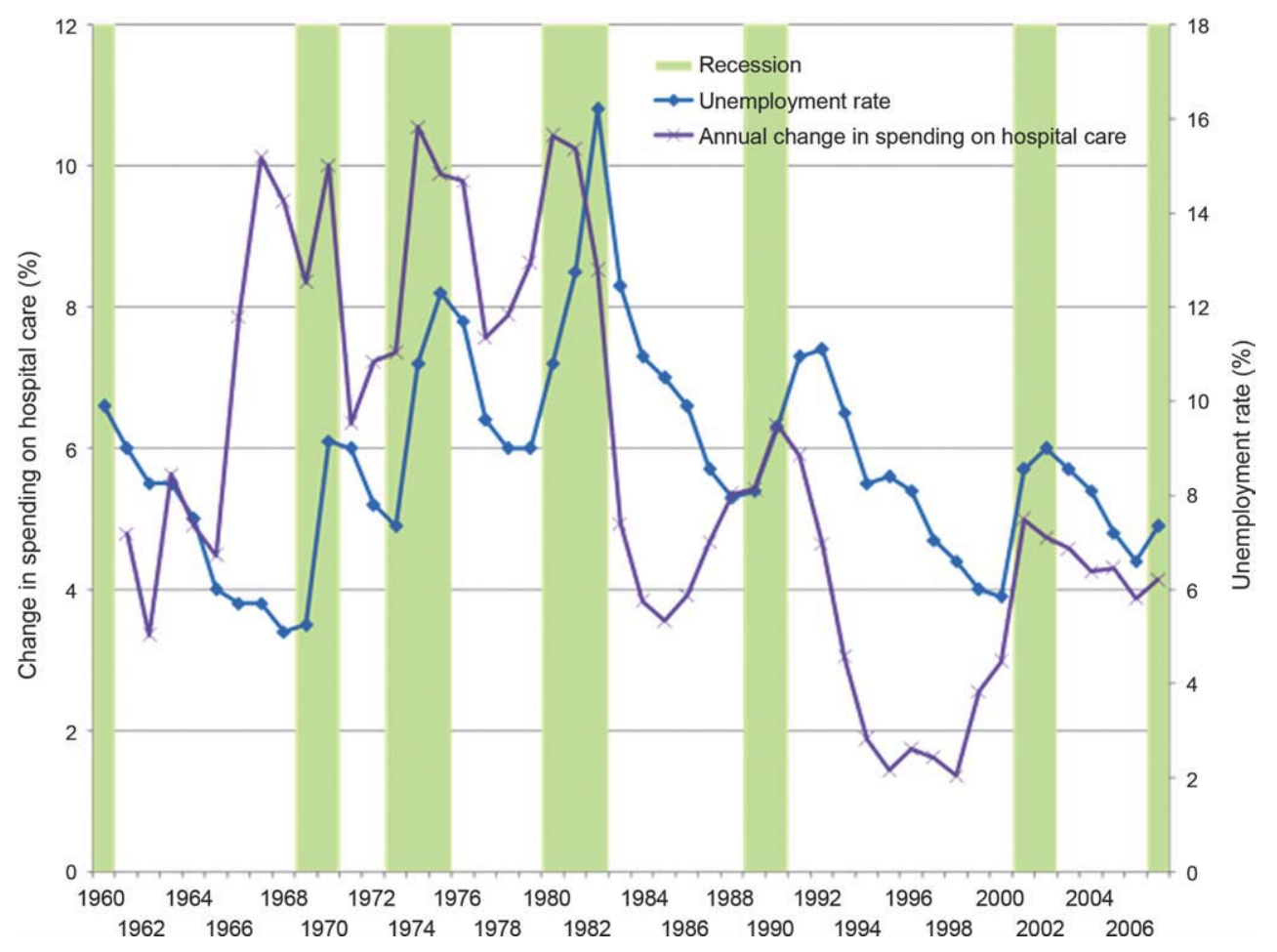

FIGURE 1. Relationship between spending on hospital care and unemployment rate.

problems), and charitable donations. ${ }^{4}$ Over $50 \%$ of US hospitals had negative margins in the fourth quarter of 2008, though there has been some improvement since that time. ${ }^{8}$

Future hospital stability concerns remain. Growth in revenue per discharge is still below the norm. ${ }^{5}$ Because employment lags a recovering economy, further reimbursement decreases are possible from increasing proportions of patients with low-reimbursing insurers or no coverage at all, decreasing payment rates from all payers, and decreasing elective care. The lower-reimbursing payers, like state Medicaid programs, are experiencing increased enrollment as Americans lose their jobs and their better-paying, employersponsored private insurance. ${ }^{9}$ There's also evidence that reimbursement rates are declining from both Medicare and private insurers, ${ }^{10}$ which threatens the fragile cost-shift through which hospitals have long used private insurance reimbursement to subsidize government reimbursements. ${ }^{11}$

Hospitals' specific financial challenges will likely vary across markets. The authors' state of Michigan has been hit particularly long and hard by the current recession. Unemployment rates exceeding $11 \%$ are expected to cause dramatic losses in private health insurance. ${ }^{9}$ Patients' increasing need with decreasing ability to pay will make markets in the deepest recession particularly vulnerable.

\section{Hospital Quality and Safety at Risk?}

The effect of the recession on the quality of hospital care is less clear. Until the 1990s, hospital quality was essentially assumed and virtually unmeasured. Even now, measuring hospital quality is difficult and rarely timely. Medicare data often take 1 to 2 years to become publicly available for analysis. Reports by trade organizations like the American Hospital Association are up-to-date but have conflicts of interest and are less rigorous. The most timely measures of hospitals' distress-flawed as they may be-will come from the hospitals themselves, just like reports of economic woe from other businesses and government agencies during challenging economic times.

However, since the publication of the 1999 report To Err is Human, ${ }^{12}$ major improvements in hospital quality and safety have transformed the delivery of inpatient care. These improvements have taken the form of simple interventions like nationally consistent medical abbreviations, management initiatives like Six Sigma, and technological advances including computerized health records.

Nonetheless, during this recession and recovery, slashed hospital budgets may slow or even stop the momentum towards further improvements in quality and safety. Frontline care delivery could be at risk. Understaffed and under financed hospitals are rarely safe. Dissatisfaction and layoffs hurt the interactions between employees and patients. Robust nurse-to-patient ratios which have proven vital to patients' hospital outcomes could be at risk. ${ }^{13}$ Admittedly, recession-induced threats to quality and safety are conjectures on our part: unfortunately, no recession measures of hospitals' specific spending on staffing, technology, or process improvements exist.

However, there are many small, evidence-based changes that could improve hospital safety dramatically in the near future. Michigan's Keystone ICU Initiative showed that 
systematic interventions in routine care delivery could reduce the risk of catheter-related bloodstream infections, which currently are implicated in the death of 28,000 Americans per year, to nearly zero. ${ }^{14}$ The Institute for Healthcare Improvement's 100,000 Lives Campaign also illustrated that dramatic improvements in hospital-related mortality can occur with fairly focused interventions. In the month after discharge, more than one-quarter of all hospitalized patients go to an emergency room or need to be rehospitalized. This rate can be cut by $30 \%$ by inserting a "nurse discharge advocate" into the discharge process. ${ }^{15}$ Instituting a simple safety checklist before surgery decreased surgery-related mortality and complications by over one-third. ${ }^{16}$

Such interventions are effective, reasonable, and widely accessible. Over the long-term, many may even be cost-saving. But, importantly, they all require an institutional investment in start-up money and an organizational will to change how things have been done. In a period of recession with severe cost-cutting, and a recovery period of cautious spending, this may not be possible.

\section{A Possible Stimulus: Investing in Quality Initiatives at Fiscally Vulnerable Hospitals}

It is not enough to keep hospitals' doors open in a recession. Hospitals must continue to improve the quality and safety of the care they deliver-vital for their future patients and also for their communities who depend on them as anchors of health systems. We believe there is a need for a new, federally supported alignment of hospital finance and hospital quality that can limit damage to hospitals, help community employment, and improve patient safety.

Timely, structural quality measures could speed the introduction of functional value-based purchasing, promote hospital safety, and help local economies at the same time. There are many simple structural measures that could be examined, such as development of discharge coordinators, promoting effective nurse-to-patient ratios, and encouraging health information technology (IT). Importantly, this would not duplicate efforts already underway to promote quality with process measures. With effective financial monitoring in real time, these measures could focus on high-risk, fiscally disadvantaged hospitals.

To its credit, the Obama administration has already reached out to support hospitals, although aid has not been targeted specifically to hospitals in the most dire financial circumstances. Along with support for Medicaid and community health centers to improve primary care during the recession, the administration has provided a \$268 million increase in Disproportionate Share Hospital payments towards hospitals that care for vulnerable patients, an increase of about $3 \% .{ }^{17}$ Concurrently, the Centers for Medicare and Medicaid Services are implementing a value-based purchasing program that starts with a $5 \%$ withhold in reimbursement that institutions need to earn back through a combination of mortality, process, and patient satisfaction metrics. ${ }^{18}$ The administration also reserved $\$ 19$ billion to promote improvement of health IT for American medicine. ${ }^{19}$

Using health IT investment to help hospitals is an appealing concept, but for many institutions the infrastructure required to make that transition directly competes with other patient needs, including bedside patient care. IT investments have large initial costs, at a time when bank loans are difficult to acquire and few organizations can make expensive capital improvements. In fact, one-quarter of hospitals report scaling back health IT investments that they had already started, in spite of the stimulus funds available. ${ }^{4}$

Instead, the administration may have more influence on improving care delivery by focusing on connecting hospital safety with hospital financial stability, by appropriating stimulus funds to center on quality and safety programs like those described above. Here is how: a hospital that would receive stimulus money for employing nurse discharge advocates would preserve employment while advancing patient safety, as would a hospital that retains a nurse-topatient ratio above a specified threshold. By focusing on measures of structural quality, the government could improve care in ways that are easy to measure and maximize local economic stimulus without difficult outcomes assessment, insurance reform, or duplicating process measure efforts. There could even be an innovation differential (ie, payment/reward) for hospitals that improve quality while holding flat or lowering overall costs.

Equally important is to use this national financial crisis as an opportunity to improve monitoring of hospital quality. While quality assessment of hospitals is difficult, increased federal awareness of local medical need, hospital financial stability, and government awareness of emergency services overcrowding, nurse-to-patient ratios, and IT utilization are all valuable and easy to measure.

None of these quality-focused fiscal interventions would be guaranteed to prevent hospital closure. Especially in small population centers, hospital closures can affect an entire community's financial growth and clinical safety net, ${ }^{20}$ while leaving hundreds or even thousands unemployed. Hospital closure should be assessed by state and federal government officials in these larger terms, perhaps even encouraging closure when appropriate, and helping prevent it when necessary.

\section{Conclusion}

Hospitals, as complex pieces of America's health care system, are central to communities' safety and economic growth. While national health coverage reform, as currently being discussed in Washington, would make hospital infrastructure less sensitive to macroeconomic changes, major reform would not come fast enough if hospitals start closing. While the worst of the recession may be over, recovery and the continuing rise in unemployment is a tenuous lifeline for hospitals on the financial brink. 
We are not arguing against all hospital layoffs, or even closures. Indeed, this recession is a lean time for most industries and is likely to lead to closures for hospitals that cannot compete on efficiency or quality. But a hospital closure is a major event for a community and should not be permitted to occur without thorough consideration of alternatives. Current data on hospitals' financial status and clinical safety are limited, potentially biased, and not timely enough for this rapidly changing economic crisis. Therefore, state and federal government officials should assess whether hospitals would be eligible not just for possible emergency loans, but for linking loans to quality of care and community need. In so doing, this difficult time could be an opportunity to help hospitals improve their care, rather than watching it diminish.

\section{Address for correspondence and reprint requests:}

Jeremy B. Sussman, MD, MS, 6312 Medical Science Building 1, 1150 W. Medical Center Dr. Ann Arbor, MI 48109;

Telephone: 734-647-4844; Fax: 734-647-3301;

E-mail: jeremysu@med.unich.edu Received 17 June 2009; revision received 21 October 2009; accepted 26 November 2009.

\section{References}

1. Michigan's Health Care Safety Net: In Jeopardy. 2009.

2. Levy P. Final budget decisions. Running A Hospital. Vol 2009. Boston, MA; 2009.

3. Burton TM. Doctors Plan to Limit Beds in ER. Wall Street Journal. 2009.

4. The Impact of the Economic Crisis on Health Services for Patients and Communities. Washington, DC 2009.

5. Koepke D, Pickens G. Hospital Operational and Financial Performance Improving. Ann Arbor, MI: Thomson Reuters Center for Healthcare Improvement. 2009.
6. Starr P. The Social Transformation of American Medicine. New York, NY: Basic Books; 1983.

7. AAFP. Patient Care during the 2008-2009 Recession - Online Survey. Leawood, KS: AAFP. 2009.

8. The Impact of the Economic Crisis on Health Services for Patients and Communities. Washington, D.C.: American Hospital Association. 2009.

9. The economic downturn and its impact on hospitals. American Hospital Association Trendwatch. 2009.

10. Dunn D, Koepke D, Pickens G. The Current Recession and U.S. Hospitals: Center for Healthcare Improvement. 2009.

11. Dobson A, Davanzo J, Sen N. The cost-shift payment 'hydraulic': foundation, history, and implications. Health Aff (Millwood). 2006;25(1):22-33.

12. Kohn KT CJ, Donaldson MS. To Err Is Human: Building a Safer Health System. Washington, DC: National Academy Press; 1999.

13. Needleman J, Buerhaus P, Mattke S, Stewart M, Zelevinsky K. Nurse-staffing levels and the quality of care in hospitals. $N$ Engl J Med. 2002; 346(22):1715-1722.

14. Pronovost P, Needham D, Berenholtz S, et al. An intervention to decrease catheter-related bloodstream infections in the ICU. $N$ Engl J Med. 2006; 355(26):2725-2732.

15. Jack BW, Chetty VK, Anthony D, et al. A reengineered hospital discharge program to decrease rehospitalization: a randomized trial. Ann Intern Med. 2009;150(3):178-187.

16. Haynes $A B$, Weiser TG, Berry WR, et al. A surgical safety checklist to reduce morbidity and mortality in a global population. $N$ Engl J Med. 2009;360(5):491-499.

17. Disproportionate Share Hospital (DSH). Available at: http://www.hhs. gov/recovery/cms/dsh.html. Accessed December 2009.

18. Tompkins CP, Higgins AR, Ritter GA. Measuring outcomes and efficiency in medicare value-based purchasing. Health Aff (Millwood). 2009;28(2): w251-w261.

19. Blumenthal D. Stimulating the adoption of health information technology. N Engl J Med. 2009;360(15):1477-1479.

20. Holmes GM, Slifkin RT, Randolph RK, Poley S. The effect of rural hospital closures on community economic health. Health Serv Res. 2006;41(2): 467-485. 